\title{
Erratum
}

\section{Burgess Reagent: From Oblivion to Renaissance in Organic Synthesis}

Santra, S. Synlett 20009, 328.

In Abstract J it should read "sulfilimines" instead of "sulfimines" and "sulfoxides" instead of "solfoxides". Furthermore, in Abstract E the compound numbering in the Scheme was incorrect. The correct Scheme is shown below.

a) 2 , THF $70{ }^{\circ} \mathrm{C}$ b) $\mathrm{PhCO}_{2}-\mathrm{NH}_{4}{ }^{+}$

c) $\mathrm{H}_{2} \mathrm{SO}_{4}$

$43 \%$
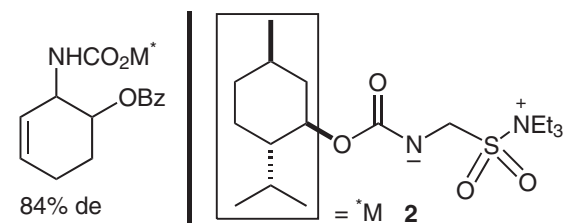